\title{
Relationship between occlusal force and falls among community-dwelling elderly in Japan: a cross-sectional correlative study
}

\author{
Maki Eto ${ }^{1}$ and Shinji Miyauchi ${ }^{*}$ (D)
}

\begin{abstract}
Background: Falls may cause serious health conditions among older population. Fall-related physical factors are thought to be associated with occlusal conditions. However, few studies examined the relationship between occlusal force and falls. To identify the association between occlusal force and falls among community-dwelling elderly individuals in Japan, public health nurses conducted a cross-sectional descriptive study.
\end{abstract}

Methods: We performed extensive physical assessments of five items: maximum occlusal force, handgrip strength, maximal knee extensor strength, one-leg standing time with eyes open and body sway. We also conducted a questionnaire survey concerning the participants' demographic characteristics, health status and fall experience during the past year. Mean scores and standard deviations were calculated for age and the total points of the index of activities of daily living. Associations were examined using Mann-Whitney tests and logistic regression.

Results: We examined 159 community-dwelling people aged $\geq 65$ years, who were independent and active, including 38 participants (24.5\%) with experience of falls in the past year. Maximum occlusal force had significant correlation with handgrip strength, maximal knee extensor strength, and one-leg standing time and body sway $(P<.05$, respectively). We found weak associations between participants with and without a history of falls in terms of the five physical measurements. Logistic regression analysis showed that fall experience was significantly associated with maximum occlusal force $(P=0.004)$.

Conclusions: This is the first study, led by public health nursing researchers, to examine the associations between maximum occlusal force and falls among community-dwelling elderly in Japan. The results showed that maximum occlusal force was significantly related to the other four extensive physical assessments, and might also suggest that maximum occlusal force assessment by public health nurses could contribute to more sophisticated and precise prediction of fall risks among the community-dwelling elderly. The latest occlusal force measurement device is noninvasive and easy to use. Public health nurses can introduce it at periodical community health checkup assembly events, which might contribute to raising awareness among community-dwelling elderly individuals and public health nurses about fall prevention and prediction.

Keywords: Community-dwelling elderly, Falls, Occlusal force, Public health nurses

\footnotetext{
*Correspondence: miyauchi@oita-nhs.ac.jp

${ }^{2}$ Division of Linguistics, Department of Health Sciences, Oita University of

Nursing and Health Sciences, 2944-9 Megusuno, Oita 870-1201, Japan

Full list of author information is available at the end of the article
}

C The Author(s). 2018 Open Access This article is distributed under the terms of the Creative Commons Attribution 4.0 International License (http://creativecommons.org/licenses/by/4.0/), which permits unrestricted use, distribution, and reproduction in any medium, provided you give appropriate credit to the original author(s) and the source, provide a link to the Creative Commons license, and indicate if changes were made. The Creative Commons Public Domain Dedication waiver (http://creativecommons.org/publicdomain/zero/1.0/) applies to the data made available in this article, unless otherwise stated. 


\section{Background}

Falls are likely to lead to serious or deadly health conditions among older populations in aging societies [1-3]. Major factors related to falls include muscle strength [4, 5] and balance ability [6-8], which have significant associations with occlusal conditions or occlusal force [9]. For example, handgrip force is an upper extremity muscle strength parameter that is significantly associated with occlusal force among older community-dwelling women [10], among the oldest community-dwelling men [11], and among elderly community-dwelling individuals [12]. Okuyama et al. [13] showed that partial or complete lack of teeth among elderly community-dwelling individuals was significantly associated with lower extremity muscle strength. As a balance ability index, one-leg standing time with eyes open is also significantly associated with occlusal force among older populations [10-15]. Yoshida et al. [16] indicated a significant association between the deterioration of occlusal conditions and the number of falls among elderly individuals with dementia.

Public health nurses (PHNs) in Japan have a role in promoting health and preventing diseases in the community by planning, implementing, and evaluating community health programs for the elderly, including fall prevention programs [17, 18]. Regular health examinations for the elderly population are planned through the community health authority and implemented by PHNs. Hirao et al. [10] and Yoshida et al. [16] argued that dental examinations should be included during this regular health checkup for older community- dwelling people. However, to our knowledge, there are few PHN-led studies concerning occlusal force or conditions and few studies related to the association between occlusal force and falls among community-dwelling elderly. Therefore, the aim of this PHN-led study was to examine the associations between maximum occlusal force (MOF) and falls among community-dwelling elderly in Japan and to discuss the possible availability and profitability of occlusal force assessment by PHNs to prevent falls in the community.

\section{Methods}

\section{Recruitment and sample}

We selected a city in southwestern Japan with a population of approximately 170,000 and explained the aim of our study entitled "survey of health conditions and falls among the community-dwelling elderly in a Japanese city" to the health care department of the city office. With support from the department, we recruited volunteer study participants $(N=159)$ who were community residents, 65 years or older, and able to perform activities of daily living (ADL) independently. We described the objectives and procedures of the study to the participants and obtained signed informed consent forms from them.

\section{Data collection}

We used a cross-sectional descriptive correlative approach as the study design. We scheduled study gatherings at nine different community halls in the city from February 17 to March 31, 2014. Each participant chose a convenient time and visited the study site using their own mode of transportation, including walking. There were two measurements, extensive physical assessments of five items including MOF, which took approximately $30 \mathrm{~min}$ (Additional file 1), and a questionnaire concerning the demographic characteristics and health status of the participants, which also took approximately $30 \mathrm{~min}$ (Additional file 2).

As extensive physical assessment, we measured five items: MOF, handgrip strength, maximal knee extensor strength, one-leg standing time with eyes open and body sway. Moon \& Lee [9] described the definition of occlusion as contact between the maxillary and mandibular teeth during chewing or at rest. Therefore, in this study, we defined occlusal force as the force produced by occlusion. MOF $(\mathrm{kN})$ was measured according to a standard procedure using an occlusal force-measuring device (GM10 Morita Occlusal Force Meter; J. Morita Corporation, Tokyo, Japan). Dentures were worn when present. MOF measurement was performed with the participants in an unsupported, natural seated position. We explained the measurement method before it was performed. We did not obtain MOF measurements from participants who reported pain at the beginning of the measurement. We also asked the participants to stop biting as soon as they felt pain or discomfort. MOF was measured unilaterally on the right and left sides at the molar. The maximum value of either the right or the left measurement was used as the MOF value.

Handgrip strength values $(\mathrm{kg})$ of the dominant and non-dominant hands were alternately measured, using Takei Digital Hand Grip Dynamometer T.K.K. 5401 (Takei Scientific Instruments Co., Ltd., Niigata, Japan), during two trials with each patient in an unsupported, natural standing position. The maximum value of either the right or the left measurement was used as the handgrip strength value.

Maximal knee extensor strength $(\mathrm{kg})$ was measured using $\mu$ Tas MF-1 (Anima Co. Ltd., Tokyo, Japan). The participants sat on a chair and held both hands behind their back to support their upper body. The thighs, knees, and ankles were held at a right angle. A sensor pad was attached to the lower front of the shin with an elastic band, and the band was looped around the leg of the chair. We asked the participants to kick their leg with the sensor pad as hard as possible and to keep that strength for five seconds. The trials were conducted twice for the right and left legs. We also asked the participants to breathe out when kicking to reduce the burden on the heart and to stop the trial when they felt 
pain or discomfort. The maximum value of either the right or the left measurement was used as the knee extensor strength value.

One-leg standing time with eyes open was measured with the hands on the waist while standing on one foot while the other foot was off the floor. The time (seconds) was recorded until the participants lost their balance, began to hop around, moved their hands off the waist, or lowered the raised foot to the floor. They performed one trial for the right foot first; after a 10-s break, they did the same with the left foot. The highest value of either the right or the left measurement was used as the time for one-leg standing, with a maximum score of $120 \mathrm{~s}$.

The total length of body sway was measured using a 5- $\mathrm{km} / \mathrm{h}$ moving image $(\mathrm{cm}$ ), Gravi Coda GS3000 (Anima Co., Ltd., Tokyo, Japan), and Eye Trek FMD-150 W (Olympus, Tokyo, Japan). First, the body sway of participants was measured for $30 \mathrm{~s}$ in a natural standing position with the eyes open. After $30 \mathrm{~s}$ of rest, participants put the Eye Trek gear on their head. As they watched an image moving $5 \mathrm{~km} / \mathrm{h}$ through the gear, their body sway was measured for $30 \mathrm{~s}$ by following a certain point of the body surface. We calculated the total length of the movement of the point as the body sway value. When we performed the body sway measurement, all participants were supported by research assistants standing beside and behind them on the equipment to prevent them from falling. We did not perform the measurement for participants who claimed a tendency for motion sickness, medical history of cerebrovascular disease or epilepsy, or anxiety regarding their health status. Fortunately, we found no such cases.

For the safety of participants and precise data collection, we trained 13 research assistants, including three licensed registered nurses, for one week to skillfully perform the extensive physical assessments. Each assistant was in charge of his/her specific assessment item only. Reproducibility of measurements was examined using peer measurements. We confirmed that the skill levels of the assistants were satisfactory.

We developed our original questionnaire, including previous research regarding health status and falls among the community-dwelling elderly. The questionnaire items were as follows: age; sex; history of disease; denture use; regular/ routine exercise habits such as walking, jogging, or playing sports; ADL using the Tokyo Metropolitan Institute of Gerontology Index of Competence (TMIG-IC) [19, 20]; and falls during the past year. TMIG-IC, which was created in the United States in the 1970s, was modified in the 1980s to assess the competence of Japanese elderly individuals in terms of instrumental self-maintenance, intellectual activity, and social role. The index consists of 13 yes (1 point) and no (0 points) questions. Higher scores (maximum of 13 points) indicated that participants were able to perform ADL better and more independently ([21-23]. TMIG-IC also questions five items regarding quality of life: sense of subjective health, relationship with family, relationship with friends, financial satisfaction, and subjective happiness. Participants were asked to rate their values for the items using a $100-\mathrm{mm}$ visual analogue scale, with the worst value on the left end and the best value on the right.

Before implementing the structured questionnaire, research assistants were trained regarding how to help the elderly answer it. During registration at the survey gatherings, we asked participants their names and postal addresses, so that data could be returned to them after the survey. We distributed a set of data collection sheets including the structured questionnaire with an identification number for each participant. To help the participants answer the questionnaire, the research assistants sat face-to-face with them and read aloud the questions, sentences, and answers slowly. After the participants finished all the measurements and questions, the completed data collection sheets were collected by the research assistants to analyze the data. The full set of the questionnaire sheet included additional question items, which were not relevant to the present study. Therefore, we did not provide the data of those question items in this paper.

\section{Data analysis}

We obtained descriptive statistics regarding age, sex, history of disease, current disease status, denture use, presence or absence of regular/routine exercise habits or playing sports, ADL using TMIG-IC, and falls during the past year. Mean scores and standard deviations were calculated for age and the total points of the TMIG-IC. Associations were examined using Mann-Whitney tests for falls and MOF, handgrip strength, maximal knee extensor strength, one-leg standing time with eyes open, and total length of body sway using a $5-\mathrm{km} / \mathrm{h}$ moving image. We performed logistic regression to determine odds ratios (ORs) of falls. The covariates included the following five items which have significant correlation and are related with muscle: MOF, handgrip strength, maximal knee extensor strength, one-leg standing time with eyes open, and total length of body sway with a $5-\mathrm{km} / \mathrm{h}$ moving image. We performed statistical calculations using SPSS version 22.0 for Windows (IBM Japan, Tokyo, Japan) with a significance level of $P<0.05$.

\section{Ethical considerations}

All participants submitted consent forms to the study researchers. We fully disclosed the purposes and significance of the study both orally and in written form. We assured the participants that participation was voluntary 
and that they could stop their participation at any time without any disadvantages. It was ensured that we would keep the data anonymous and confidential and would limit data use only to the study. All participants, research staff, and measurement instruments were insured against accidents. The study was formally approved by the institutional review board of the author's university.

\section{Results}

\section{Characteristics of participants}

We examined a total of 159 participants; 56 were male $(35.2 \%)$ and 103 were female (64.8\%). The average age was $75.7 \pm 6.8$ years for men; it was $73.5 \pm 6.1$ years for women. Ninety participants $(56.6 \%)$ had a history of diseases and 131 (82.4\%) had current diseases. Ninety-eight people (61.6\%) performed regular physical exercise. Male participants had an average TMIG-IC score of $12.25 \pm 1$. 16 and female participants had an average TMIG-IC score of $12.20 \pm 1.19$ on a scale of 0 to 13 . Of these participants, $38(24.5 \%)$ experienced falls in the past year. Sixty-five participants (40.9\%) wore dentures.

\section{Extensive physical assessments and falls}

The average strength values of MOF with and without falls were $0.35 \pm 0.23 \mathrm{kN}$ and $0.25 \pm 0.20 \mathrm{kN}$, respectively. The average strength values for handgrip of the participants with and without falls were $27.50 \pm 7.87 \mathrm{~kg}$ and 30 . $41 \pm 9.26 \mathrm{~kg}$, respectively. For maximal knee extensor strength, the average scores of the participants with and without falls were $13.87 \pm 7.28 \mathrm{~kg}$ and $11.70 \pm 5.40 \mathrm{~kg}$, respectively. In terms of body balance, the average oneleg standing times with eyes open for those with and without falls were $46.47 \pm 50.82 \mathrm{~s}$ and $62.58 \pm 79.62 \mathrm{~s}$, respectively. For total length of body sway, the average scores for those with and without falls were $42.04 \pm 16$. $32 \mathrm{~cm}$ and $50.05 \pm 19.04 \mathrm{~cm}$, respectively. Regarding the five items of physical assessment, MOF had significant correlation with handgrip strength, maximal knee extensor strength, and one-leg standing time $(P<.01$, respectively), and with body sway $(P<.05)$ (Table 1$)$. We found weak associations between participants with and without a history of falls (Table 2).

\section{Associations of falls with measurement items}

Logistic regression analysis showed that fall experience was significantly associated with MOF (OR, 0.49; 95\% confidence interval [CI]: 0.09-2.62; $P=0.004)$, handgrip strength (OR, 0.39; 95\% CI, 0.17-0.90; $P=0.027$ ), maximal knee extensor strength (OR, 2.04; 95\% CI, 1.17-3. 55; $P=0.012)$, and one-leg standing time (OR, 8.40; $95 \%$ CI, $1.10-64.26 ; P=0.040)$. In this study, there was no significant association between falls and the average total length of body sway with a $5-\mathrm{km} / \mathrm{h}$ moving image (OR, 3.44; 95\% CI, 0.38-31.53; $P=0.072$ ) (Table 3). The values of $\mathrm{C}$ statistic concerning the five items are as follows: MOF, 0.648; handgrip strength, 0.578; maximal knee extensor strength, 0.608; one-leg standing time, 0 . 533; and the average total length of body sway with a 5$\mathrm{km} / \mathrm{h}$ moving image, 0.654 .

\section{Discussion}

This study sought to examine the associations between extensive physical assessments including MOF and fall experience among elderly community-dwelling individuals. High scores on the TMIG-IC in terms of the quality of ADL seemed to indicate that participants were healthy and active, and had similar physical and functional characteristics.

The result of our study showed that MOF was significantly related to the other four extensive physical assessments. With regard to hand-grip strength, lower extremity strength and one-leg standing time, the result was similar to that in the previous study [15]. We identified significant tendencies between the participants with fall experience and those without it in terms of all the extensive physical assessments. However, logistic regression analysis revealed that MOF had the second strongest association with falls, after knee extensor strength. The results of this study not only supports the argument in the previous study [14] that examining MOF is appropriate for determining the functional abilities of the lower extremities and body balance, but might also suggest that MOF assessment itself could contribute to predicting fall risks among the community-dwelling elderly. Abe et al. [24] also contended that the assessment

Table 1 Correlative analysis among extensive physical assessments

\begin{tabular}{|c|c|c|c|c|c|c|c|c|}
\hline & Occlusal force & Handgrip strength & $\begin{array}{l}\text { Knee extensor } \\
\text { strength }\end{array}$ & $\begin{array}{l}\text { One-leg standing } \\
\text { with open eyes }\end{array}$ & $\begin{array}{l}5 \mathrm{~km} / \mathrm{h} \text {-image body } \\
\text { sway: total length }\end{array}$ & $\mathrm{N}$ & M & SD \\
\hline Occlusal force & - & & & & & 155 & .27 & .21 \\
\hline Handgrip strength & $.382 * *$ & - & & & & 157 & 28.79 & 8.55 \\
\hline Knee extensor strength & $.263 * *$ & $.457 * *$ & - & & & 157 & 11.63 & 5.68 \\
\hline $\begin{array}{l}\text { One-leg standing with } \\
\text { open eyes }\end{array}$ & $.369 * *$ & $.129 *$ & $.202 *$ & - & & 157 & 55.38 & 71.59 \\
\hline $\begin{array}{l}5 \mathrm{~km} / \mathrm{h} \text {-image body } \\
\text { sway: total length }\end{array}$ & $-.196 *$ & $.070 *$ & -.096 & $-.291 * *$ & - & 157 & 47.72 & 17.63 \\
\hline
\end{tabular}

Pearson product-moment correlation coefficient, ${ }^{* *}: P<0.01,{ }^{*}: P<0.05 . \mathrm{M}$ stands for mean. SD stands for standard deviation 
Table 2 Extensive physical assessments: with or without experience of falls

\begin{tabular}{|c|c|c|}
\hline With experience $(n=38)$ & Without experience $(n=121)$ & $P$-value \\
\hline \multicolumn{3}{|c|}{ Maximum occlusal force, mean $\mathrm{kN} \pm \mathrm{SD}$} \\
\hline $0.35 \pm 0.23$ & $0.25 \pm 0.20$ & .051 \\
\hline \multicolumn{3}{|c|}{ Handgrip strength, mean $\mathrm{kg} \pm \mathrm{SD}$} \\
\hline $27.50 \pm 7.87$ & $30.41 \pm 9.26$ & .156 \\
\hline \multicolumn{3}{|c|}{ Knee extensor strength, mean $\mathrm{kg} \pm \mathrm{SD}$} \\
\hline $13.87 \pm 7.28$ & $11.70 \pm 5.40$ & .068 \\
\hline \multicolumn{3}{|c|}{ One-leg standing, mean sec \pm SD } \\
\hline $46.47 \pm 50.82$ & $62.58 \pm 79.62$ & .101 \\
\hline \multicolumn{3}{|c|}{$5 \mathrm{~km} / \mathrm{h}$-image body sway: total length, mean $\mathrm{cm} \pm \mathrm{SD}$} \\
\hline $42.04 \pm 16.32$ & $50.05 \pm 19.04$ & .062 \\
\hline
\end{tabular}

of fall risks could be more sophisticated and exact by combining examinations of lower extremity muscle strength and balance ability. Our study suggests that adding MOF assessment to the examinations of lower extremity strength and balance ability could make the potential of fall risk prediction much more sophisticated and precise.

We found that the MOF average score among participants with fall experience was higher than that of participants without falls: $0.35 \pm 0.23 \mathrm{kN}$ and $0.25 \pm 0.20 \mathrm{kN}$, respectively. This might be because participants with a partial lack of teeth put more pressure on the remaining teeth than do participants with all their teeth. Song-Yu et al. [8] reported that elderly individuals with a partial lack of teeth had significantly less stable posture. Proper clenching excites the human motor system and affects human postural control [25]. In this study, we did not examine the relationship between MOF and denture use or between MOF and the number of remaining teeth. However, due to the higher MOF scores among participants with fall experience, we suggest that they have unfavorable dental conditions that might have affected their balance ability [13], resulting in falls. It is also

Table 3 Odds ratio between fall experience and extensive physical assessments $(n=159)$

\begin{tabular}{|c|c|c|c|c|c|}
\hline \multirow[t]{2}{*}{ Measures } & \multirow[t]{2}{*}{ Mean } & \multirow{2}{*}{$\begin{array}{l}\text { Odds } \\
\text { ratio }\end{array}$} & \multicolumn{2}{|c|}{$95 \% \mathrm{Cl}$} & \multirow[t]{2}{*}{ P-value } \\
\hline & & & low & upper & \\
\hline Maximum occlusal force & 0.27 & .49 & .09 & 2.62 & $.004^{*}$ \\
\hline Handgrip strength & 28.69 & .39 & .17 & .90 & $.027^{*}$ \\
\hline Knee extensor strength & 11.62 & 2.04 & 1.17 & 3.55 & $.012^{*}$ \\
\hline $\begin{array}{l}\text { One-leg standing with } \\
\text { open eyes }\end{array}$ & 55.40 & 8.40 & 1.10 & 64.26 & $.040^{*}$ \\
\hline $\begin{array}{l}5 \mathrm{~km} / \mathrm{h} \text {-image body } \\
\text { sway: total length }\end{array}$ & 52.11 & 3.44 & .38 & 31.53 & $.072^{*}$ \\
\hline
\end{tabular}

Logistic regression, ${ }^{*} P<0.05$. $\mathrm{Cl}$ stands for confidence interval implied that bite adjustment or denture use may improve postural control.

The device used to measure occlusal force in this study, GM10, is a portable tool that is easy to use and inexpensive. It is also less invasive physically and psychologically for those who undergo MOF measurements [12]. It can obtain objective data instead of subjective (and sometimes false) individual perceptions of MOF [26]. By using this handy tool, PHNs can easily assess MOF among elderly community-dwelling individuals. PHNs can collect data during regular community health check-ups, share and analyze the data, and recognize the tendencies of MOF conditions among the communitydwelling elderly. This may lead PHNs to provide individual advice to each of the elderly individuals and to raise awareness on oral health among them [16], which could potentially help to prevent future falls and reduce health care expenditures. PHNs could also share up-to-date information about risk of falls in the community with other healthcare professionals. Therefore, PHNs should check the MOF of the elderly to raise awareness on fall prevention.

One of the potential confounders on the association between occlusal force and falls is bone calcium. A systematic literature review discusses usefulness of bone density measurement in fallers in France [27]. Another review shows the evidence for the value of calcium supplementation for healthy musculoskeletal ageing [28]. However, the present study focused on extensive physical functions, which PHNs might be able to instruct directly to the community-dwelling elderly for healthcare. Thus, we did not discuss bone calcium as a confounder on the association.

\section{Study limitations}

This study had several limitations. First, the sample was small and limited to a population of only one city in Japan, which means that elderly individuals living in different areas could have had different experiences. Besides, the demographic characteristics of the sample do not seem to reflect those of the whole Japanese elderly population in terms of age, sex and comorbidity. Thus, it is not appropriate to generalize the results of the present study. Second, the study participants were relatively active community-dwelling elderly. Therefore, generalization of the present discussion cannot be applied to vulnerable and frail populations in the community, such as those with lower levels of ADL. Third, this study used a cross-sectional survey approach, using sample extracted from a limited area of a particular city in Japan. This means that the study design cannot refer to the cause and effect between MOF and falls. A prospective follow-up cohort study should be conducted to 
determine the cause-effect relationship between changes in MOF and falls.

\section{Conclusions}

This is the first study conducted by public health nursing researchers, which examined the associations between MOF and falls among community-dwelling elderly in Japan. The results showed that MOF was significantly related to the other four extensive physical assessments, and might also suggest that MOF assessment by public health nurses could contribute to more sophisticated and precise prediction of fall risks among the community-dwelling elderly. The latest occlusal force measurement device is non-invasive and easy to use. Public health nurses can introduce it at periodical community health checkup assembly events, which might contribute to raising awareness among communitydwelling elderly individuals and public healthcare providers about fall prevention and prediction.

\section{Additional files}

Additional file 1: Physical assessment data sheet. (DOCX $17 \mathrm{~kb}$ )

Additional file 2: Questionnaire. (DOCX $20 \mathrm{~kb}$ )

\section{Abbreviations}

ADL: Activities of daily living; Cl: Confidence interval; M: Mean;

MOF: Maximum occlusal force; ORs: Odds ratios; PHNs: Public health nurses; SD: Standard deviation; TMIG-IC: Tokyo Metropolitan Institute of Gerontology Index of Competence

\section{Acknowledgements}

The authors thank all the participants for their time and the experiences they contributed with to make this study possible. The authors also express our sincere gratitude to Dr. Jill Howie Esquivel, Associate Professor/Coordinator AGACNP Program of the University of Virginia, School of Nursing, for her kind and precious advice concerning academic writing style.

\section{Funding}

This study was granted by the Japanese Ministry of Education, Science and Culture, with the reference code of C-244593455. The grant was used for payment to the research assistants at data collection. The cost of questionnaire printing and purchase of disposable parts of the occlusal forcemeasuring device were also covered by the grant.

\section{Availability of data and materials}

The dataset from this study are available from the corresponding author on reasonable request.

\section{Authors' contributions}

Study design, data collection and data analysis: ME; Literature research: ME, SM; Study supervision and manuscript writing in Japanese: ME; Manuscript writing and translation from Japanese into English: SM, ME; Critical revisions for important intellectual content: ME, SM. The authors contributed to the discussion and have seen and approved the final version of the study.

\section{Ethics approval and consent to participate}

The study was formally approved by the institutional review board of Ube Frontier University (approval number 2013005). The researcher gave oral and written information, and obtained written informed consent from all participants before the extensive physical assessment and questionnaire. Participation was voluntary and the participants gave consent for the research use of data from the extensive physical assessment and questionnaire in the manuscript.

\section{Competing interests}

The authors declare that they have no competing interests.

\section{Publisher's Note}

Springer Nature remains neutral with regard to jurisdictional claims in published maps and institutional affiliations.

\section{Author details}

${ }^{1}$ Department of Public Health Nursing, Ube Frontier University, Ube, Japan. ${ }^{2}$ Division of Linguistics, Department of Health Sciences, Oita University of Nursing and Health Sciences, 2944-9 Megusuno, Oita 870-1201, Japan.

Received: 15 January 2018 Accepted: 3 May 2018

Published online: 09 May 2018

\section{References}

1. Chen SF, Huang SF, Lu LT, Wang MC, Liao JY, Guo JL. Patterns of perspectives on fall-prevention beliefs by community-dwelling older adults: a Q method investigation. BMC Geriatr. 2016;16:132. https://doi.org/10.1186/ s12877-016-0307-1.

2. Gilasi HR, Soor H, Yazdani S, Tenjani PT. Fall-related injuries in communitydwelling older adults in Qom Province, Iran, 2010-2012. Arch Trauma Res. 2015:4(1):e22925. https://doi.org/10.5812/1tr.22925.

3. Morris JN, Howard EP, Steel K, Berg K, Tchalla A, Munankarmi A, David D. Strategies to reduce the risk of falling: cohort study analysis with 1-year follow-up in community dwelling older adults. BMC Geriatr. 2016;16:92. https://doi.org/10.1186/s12877-016-0267-5.

4. Goto J, Hosoya T, Kobayashi A, Kanoya Y, Ohtake M, Morikagi Y. Factors associated with functional capacity decline risk over 6-year period among independent elderly persons living in the community. J Jpn Acad Community Health Nurs. 2014;16(3):65-74

5. Moreland JD, Richardson JA, Goldsmith $\mathrm{CH}$, Clase CM. Muscle weakness and falls in older adults: a systematic review and meta-analysis. J Am Geriatr Soc. 2004;52(7):1121-9.

6. American Geriatrics Society. British geriatrics society and American Academy of orthopedic surgeons panel on falls prevention. Guideline for the prevention of falls in older persons. J Am Geriatr Soc. 2001;49(5):664-72.

7. Ringhof S, Stein T, Potthast W, Schindler HJ, Hellmann D. Force-controlled biting alters postural control in bipedal and unipedal stance. J Oral Rehabil. 2015;42:173-84. https://doi.org/10.1111/joor.12247

8. Song-Yu X, Rodis OM, Ogata S, Can-Hu J, Nishimura M, Matsumura S. Postural stability and occlusal status among Japanese elderly. Gerontology. 2012;29(2):e988-97. https://doi.org/10.1111/j.1741-2358.2011.00596.x.

9. Moon HJ, Lee YK. The relationship between dental occlusion/temporomandibular joint status and general body health: part 1. Dental occlusion and TMJ status exert an influence on general body health. J Altern Complement Med. 2010;17(11):995-1000. https://doi.org/10.1089/ acm.2010.0739.

10. Hirao A, Mutara S, Murata J, Kubo A, Hachiya M, Asami T. Relationships between the occlusal force and physical/cognitive functions of elderly females living in the community. J Phys Ther Sci. 2014;26:1279-82.

11. linuma $T$, Arai $Y$, Fukumoto $M$, Takayama M, Abe $Y$, Asakura $K$, Nishiwaki $Y$, Takebayashi T, Iwase T, Komiyama K, Gionhaku N, Hirose N. Maximum occlusal force and physical performance in the oldest old: the Tokyo oldest old survey on total health. J Am Geriatr Soc. 2012;60(1):68-76. https://doi. org/10.1111/j.1532-5415.2011.03780.x.

12. Laguna L, Sarkar A, Artigas G, Chen J. A quantitative assessment of the eating capability in the elderly individuals. Physiol Behav. 2015;147:274-81. https://doi.org/10.1016/j.physbeh.2015.04.052.

13. Okuyama N, Yamaga T, Yoshihara A, Nohno K, Yoshitake $Y$, Kimura Y, Shimada M, Nakagawa N, Nishimuta M, Ohashi M, Miyazaki H. Influence of dental occlusion on physical fitness decline in a healthy Japanese elderly population. Arch Gerontol Geriatr. 2011;52:172-6. https://doi.org/10.1016/j. archger. 2010.03.011

14. Yamaga $T$, Yoshihara A, Ando $Y$, Yoshitake $Y$, Kimura $Y$, Shimada M, Nishimuta M, Miyazaki H. Relationship between dental occlusion and physical fitness in an elderly population. J Gerontol Med Sci. 2002; 57(9):M616-20 
15. Yamashita Y, Kogo H, Kawaguchi N, Toriyama H, Mizota K. Usefulness of occlusal force measurement as a fall risk assessment tool. Rigakuryoho Kagaku (Physical Therapy Science). 2016;31(2):303-7.

16. Yoshida M, Morikawa H, Kanehisa Y, Taji T, Tsuga K, Akagawa Y. Functional dental occlusion may prevent falls in elderly individuals with dementia. J Am Geriatr Soc. 2005;53(9):1631-2.

17. Yamashita M, Miyaji F, Akimoto R. The public health nursing role in rural Japan. Public Health Nurs. 2005;22(2):156-65.

18. Yuasa $\mathrm{M}$, Ikeno $\mathrm{T}$, Ueki S. A qualitative study on perceived changes and improvement in the current state of public health activities of public health nurses in Hokkaido, Japan. Nihon Koshu Eisei Zasshi. 2011;58(2):116-28.

19. Fujiwara $Y$, Shinkai S, Amano H, Watanabe S, Kumagai S, Takabayashi K, Yoshida H, Hoshi T, Tanaka M, Morita M, Haga H. Test-retest variation in the Tokyo metropolitan Institute of Gerontology Index of competence in community-dwelling older people independent in daily living toward individual assessment of functional capacity. Nihon Koshu Eisei Zasshi. 2003:50(4):360-7.

20. Wada T, Ishine M, Ishimoto Y, Hirosaki M, Kimura Y, Kasahara Y, Okuyama K, Nishinaga M, Otsuka K, Matsubayashi K. Community-dwelling elderly fallers in Japan are older, more disabled, and more depressed than nonfallers. J Am Geriatr Soc. 2008;56(8):1571-2.

21. Inagaki H, Ito K, Sakuma N, Sugiyama M, Okamura T, Awata S. Reliability and validity of the simplified Japanese version of the WHO-five well-being index (S-WHO-5-J). Nihon Koshu Eisei Zasshi. 2013;60(5):294-301.

22. Ohura T, Higashi T, Ishizaki T, Nakayama T. Assessment of the validity and internal consistency of a performance evaluation tool based on the Japanese version of the modified Barthel index for elderly people living at home. J Phys Ther Sci. 2014;26:1971-4.

23. Tomioka K, Kurumatani N, Hosoi H. Social participation and the prevention of decline in effectance among community-dwelling elderly: a populationbased cohort study. PLoS One. 2015;10(9):e0139065. https://doi.org/10.1371/ journal.pone.0139065.

24. Abe T, Tsuji T, Soma Y, Shen S, Okura T. Composite variable of lower extremity muscle strength and balance ability for evaluating risks of mobility limitation and falls in community-dwelling older adults. J Phys Fit Sports Med. 2016;5(3):257-66. https://doi.org/10.7600/jpfsm.5.257.

25. Ringhof S, Stein T, Hellmann D, Schindler HJ, Potthast W. Effect of jaw clenching on balance recovery: dynamic stability and lower extremity joint kinematics after forward loss of balance. Front Psychol. 2016;7:291. https:// doi.org/10.3389/fpsyg. 2016.00291.

26. Cusson V, Caron C, Gaudreau P, Morais JA, Shatenstein B, Payette H. Assessing older adults' masticatory efficiency. J Am Geriatr Soc. 2015;63(6): 1192-6. https://doi.org/10.1111/jgs.13443.

27. Blain $\mathrm{H}$, Rolland $\mathrm{Y}$, Beauchet $\mathrm{O}$, et al. Usefulness of bone density measurement in fallers. Joint Bone Spine. 2014;81(5):403-8. https://doi.org/ 10.1016/j.jbspin.2014.01.020.

28. Nicholas $\mathrm{CH}$, Biver E, Kaufman J, et al. The role of calcium supplementation in healthy musculoskeletal ageing: an experts consensus meeting of the European Society for Clinical and Economic Aspects of osteoporosis, osteoarthritis and musculoskeletal diseases (ESCEO) and the International Foundation for Osteoporosis (IOF). Osteoporos Int. 2017;28(2):447-62. https://doi.org/10.1007/s00198-016-3773-6.

\section{Ready to submit your research? Choose BMC and benefit from:}

- fast, convenient online submission

- thorough peer review by experienced researchers in your field

- rapid publication on acceptance

- support for research data, including large and complex data types

- gold Open Access which fosters wider collaboration and increased citations

- maximum visibility for your research: over $100 \mathrm{M}$ website views per year

At BMC, research is always in progress.

Learn more biomedcentral.com/submissions 